\title{
Accessing Nitrosocarbonyl Compounds with Temporal and Spatial Control via the Photoredox Oxidation of $\boldsymbol{N}$-substituted Hydroxylamines
}

Charles P. Frazier, Leoni I. Palmer, Andrey V. Samoshin and Javier Read de Alaniz*

Department of Chemistry and Biochemistry, University of California, Santa Barbara, Santa Barbara, CA 93106-9510 (USA)

*Corresponding author. Fax +18058934120; email: javier@chem.ucsb.edu;

Keywords: Hydroxylamine, Nitrosocarbonyl, Photoredox, Temporal and Spatial Control, Block CoPolymer

ABSTRACT Photoredox catalysis is employed to generate highly reactive acylnitroso species from hydroxamic acid derivatives. The conditions are shown to be comparable to a previously developed transition metal aerobic oxidation and are amenable to a range of transformations including Diels-Alder and ene reactions. This unique application of such an approach gives access to temporal and spatial control in nitroso chemistry.

Nitrosocarbonyl compounds are exceptionally reactive intermediates that have found widespread use in a number of classic $\mathrm{C}-\mathrm{N}$ or $\mathrm{C}-\mathrm{O}$ bond-forming reactions, such as the ene, ${ }^{1}$ Diels-Alder, ${ }^{2}$ and aldol reactions. ${ }^{3}$ In recent years, a number of research groups have explored new methodologies to generate nitrosocarbonyl intermediates, such as oxidation under aerobic conditions, ${ }^{1-3}$ utilizing transition metals with stoichiometric peroxide, ${ }^{4}$ manganese dioxide oxidations, ${ }^{5}$ and oxidations employing TEMPO and BPO, ${ }^{6}$ among others. ${ }^{7}$ While many of these new oxidation methodologies have facilitated the expansion of nitrosocarbonyl chemistry, none have explored the potential of generating nitrosocarbonyl intermediates with temporal and spatial control. This unique property, often neglected in the context of small molecule organic synthesis, is an important facet to consider when expanding nitrosocarbonyl chemistry into biological and materials science applications.

Photoredox catalysis is an emerging tool for the synthesis of complex molecules that has been shown to be effective in contexts requiring temporal and spatial control. While the genesis of photoredox catalysis can be traced back to Kellog in the 1970's, the field has undergone a renaissance in recent years, based on the pioneering work of a number of research groups. ${ }^{8}$ In particular, the recent work by the groups of Yoon, ${ }^{9}$ and Stephenson, ${ }^{10}$ and Macmillan ${ }^{11}$ highlight the advantageous usage of photoredox catalysis in the oxidative generation of reactive intermediates. In 2012, Hawker and coworkers translated photoredox catalysis into material science, providing control of a living radical polymerization using visible light ${ }^{12}$ and subsequently demonstrated excellent spatial arrangement of functional groups at surfaces. ${ }^{13}$ The key to this methodology was visible-light mediated Ir-catalyzed atom-transfer radical addition (ATRA) chemistry developed by Stephenson and co-workers. ${ }^{14}$ Because nitrosocarbonyl compounds participate in a variety of organic reactions, the in-situ formation of this highly reactive functional group using photoredox conditions would furnish a general procedure for patterning surfaces bearing a range of properties. Moreover, because nitrosocarbonyl compounds serve as HNO donors, ${ }^{15}$ it could also provide a means to generate HNO in-situ using visible-light to control its release. To evaluate this potential, we began by investigating the in-situ generation of nitrosocarbonyl compounds using photoredox conditions. A recent report by Tan inspired us to disclose our results in this area (Figure 1). ${ }^{16}$ 


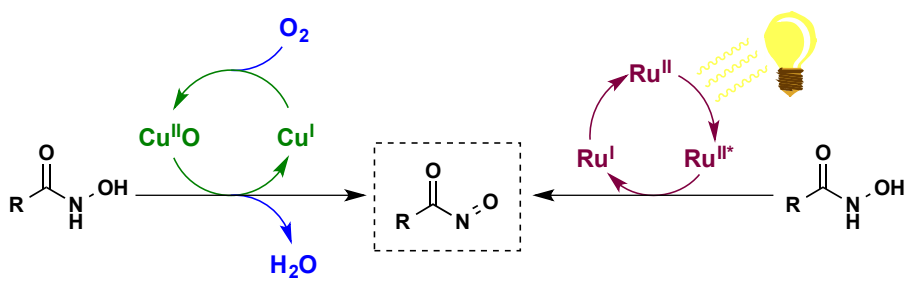

Previous Work: Aerobic Conditions

This Work: Photoredox Conditions

Advantage: temporal and spatial control

Figure 1. Exploring photoredox conditions for the generation of nitrosocarbonyls

Due to the transient nature of nitroso compounds and their associated inherent instability, ${ }^{17}$ we selected the nitroso HDA reaction to test the feasibility of a photoredox catalyst system. Nitroso compounds directly attached to an electron withdrawing group undergo rapid [4+2] cycloaddition reactions with conjugated dienes, a reaction platform that has been explored extensively by our research group $^{2 \mathrm{a}}$ and others. ${ }^{18} \mathrm{Cbz}$-protected hydroxylamine $\mathbf{1}$ and 1,3-dicyclohexadiene $\mathbf{2}$ were elected as candidates for standardizing reaction conditions (Table 1) and investigations began with commercially available and widely employed $\mathrm{Ru}(\mathrm{bpy})_{3} \mathrm{Cl}_{2} \cdot 6 \mathrm{H}_{2} \mathrm{O}$. At 1 mol \% loading and in DCE at room temperature, we were pleased to see a $35 \%$ yield of the desired oxazine product (entry 1). Analysis of the reaction mixture revealed a large amount of an undesired hetero Diels-Alder (HDA) product resulting from reaction of the diene with diatomic oxygen in a [4+2] cycloaddition and subsequent ringopening reaction, ${ }^{19}$ suggesting the potential interference of singlet oxygen on our desired reaction pathway. ${ }^{20}$ Pleasingly, the addition of pyridine (2.0 equiv) completely inhibited this unproductive pathway (entry 2) and allowed us to achieve an improved yield of $80 \%$. Screening other $\mathrm{Ru}$ photocatalysts, (entries 3-6) showed no improvement in yield or reaction duration over $\mathrm{Ru}$ (bpy) ${ }_{3} \mathrm{Cl}_{2} \bullet 6 \mathrm{H}_{2} \mathrm{O}$. In considering which photoredox catalysts to employ, $\mathrm{Ru}(\mathrm{bpy})_{3}{ }^{2+*}$ is both a good oxidant and reductant. ${ }^{8}$ Switching to a photocatalyst like $\operatorname{Ir}(\mathrm{ppy})_{3}$, which is more reducing in its excited state, had a negative impact on the yield (entries 7 and 8). Using a Eu-based catalyst (entry 9) satisfactorily augmented the yield but has the added disadvantage of requiring UV light for activation. Based on this, we elected to further optimize the reaction with $\mathrm{Ru}(\mathrm{bpy})_{3} \mathrm{Cl}_{2} \cdot 6 \mathrm{H}_{2} \mathrm{O}$.

Table 1. Optimizing photoredox conditions for the generation of nitrosocarbonyls.

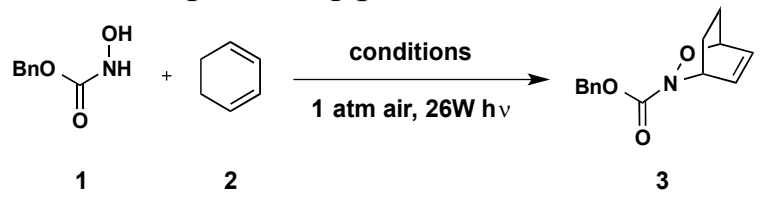

\begin{tabular}{|c|c|c|c|c|}
\hline Entry & Catalyst (1 mol \%) & Solvent & Additive (equiv) & Yield $(\%)^{a}$ \\
\hline 1 & $\mathrm{Ru}(\mathrm{bpy}){ }_{3} \mathrm{Cl}_{2} \cdot 6 \mathrm{H}_{2} \mathrm{O}$ & $\mathrm{DCE}$ & - & 35 \\
\hline 2 & $\mathrm{Ru}(\mathrm{bpy})_{3} \mathrm{Cl}_{2} \cdot 6 \mathrm{H}_{2} \mathrm{O}$ & DCE & pyridine $(2.0)$ & 80 \\
\hline 3 & $\mathrm{Ru}(\mathrm{bpz}){ }_{3} \mathrm{Cl}_{2}$ & - & - & 49 \\
\hline 4 & $\mathrm{Ru}(\mathrm{bpz}){ }_{3} \mathrm{Cl}_{2}$ & DCE & pyridine $(2.0)$ & 73 \\
\hline 5 & $\mathrm{Ru}(\mathrm{bpm})_{3} \mathrm{BArF}_{2}$ & DCE & pyridine $(2.0)$ & 30 \\
\hline 6 & $\mathrm{Ru}(\text { phen })_{3} \mathrm{Cl}_{2}$ & DCE & pyridine $(2.0)$ & 24 \\
\hline 7 & $\mathrm{Ir}-f a c(\mathrm{ppy})_{3}$ & $\mathrm{DCE}$ & pyridine $(2.0)$ & 34 \\
\hline 8 & $\operatorname{Ir}(\mathrm{BTP})_{3}$ & DCE & pyridine $(2.0)$ & 63 \\
\hline 9 & $\mathrm{Eu}(\mathrm{dbm})_{3}(\mathrm{phen})^{b}$ & DCE & pyridine $(2.0)$ & 95 \\
\hline 10 & $\mathrm{Ru}(\mathrm{bpy})_{3} \mathrm{Cl}_{2} \bullet 6 \mathrm{H}_{2} \mathrm{O}$ & DCE & 2,6-lutidine (2.0) & 87 \\
\hline 11 & $\mathrm{Ru}(\mathrm{bpy})_{3} \mathrm{Cl}_{2} \cdot 6 \mathrm{H}_{2} \mathrm{O}$ & DCE & 2,6-lutidine $(0.5)$ & 74 \\
\hline 12 & $\mathrm{Ru}(\mathrm{bpy})_{3} \mathrm{Cl}_{2} \cdot 6 \mathrm{H}_{2} \mathrm{O}$ & DCE & 2,6-lutidine $(0.05)$ & 60 \\
\hline 13 & $\mathrm{Ru}(\mathrm{bpy})_{3} \mathrm{Cl}_{2} \cdot 6 \mathrm{H}_{2} \mathrm{O}$ & $\mathrm{MeNO}_{2}$ & 2,6-lutidine (2.0) & 63 \\
\hline 14 & $\mathrm{Ru}(\text { bpy })_{3} \mathrm{Cl}_{2} \cdot 6 \mathrm{H}_{2} \mathrm{O}$ & $\mathrm{MeCN}$ & 2,6-lutidine (2.0) & 55 \\
\hline 15 & $\mathrm{Ru}(\text { bpy })_{3} \mathrm{Cl}_{2} \bullet 6 \mathrm{H}_{2} \mathrm{O}$ & DCE & 2,6-lutidine (2.0) & $<5 \%{ }^{c}$ \\
\hline
\end{tabular}




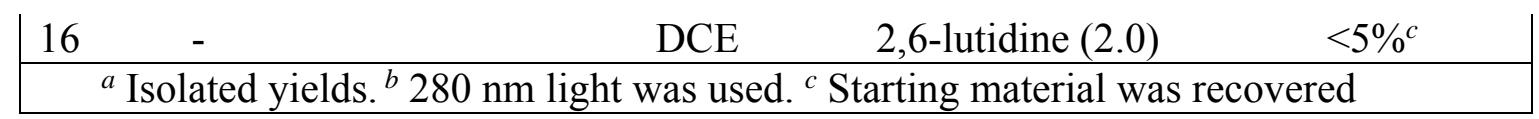

Next we looked at the dependence of the reaction on the chosen additive; screening various bases ( $\mathrm{NEt}_{3}, i \mathrm{Pr}_{2} \mathrm{NEt}$, etc.) led us to determine that 2,6-lutidine was the additive of choice for our reaction set up. Variations in the additive loading (entries 10-12) indicated 2.0 equiv of 2,6-lutidine was optimal, and a brief solvent screen (entries 13 and 14) indicated DCE to indeed be our preferred solvent. Finally, the reaction does not proceed in the dark under the same conditions and duration (entry 15), nor is any conversion observed in the absence of catalyst (entry 16). Based on these results we elected to explore the reaction with $1 \mathrm{~mol} \% \mathrm{Ru}\left(\right.$ bpy) ${ }_{3} \mathrm{Cl}_{2} \bullet 6 \mathrm{H}_{2} \mathrm{O}$ and 2 equiv 2,6-lutidine in DCE (entry 10).

With optimized reaction conditions in hand, we elected to briefly explore the scope of the DielsAlder reaction to ensure generality of reaction conditions (Table 2). To our satisfaction, both the 5- and 6-membered ring dienes readily underwent the Diels-Alder reaction with no competing production of the endoperoxide or hydroxyenone (7 and 3). Additionally, 1,4-diphenylbutadiene also underwent clean conversion to the desired oxazine product $(\mathbf{8})$. The reaction was not limited to Cbz-protected hydroxylamines, as Boc-protected hydroxylamines were readily converted to the corresponding oxazine products $(\mathbf{9}$ and $\mathbf{1 0})$.

Table 2. Scope of the nitrosocarbonyl HDA under photoredox conditions.
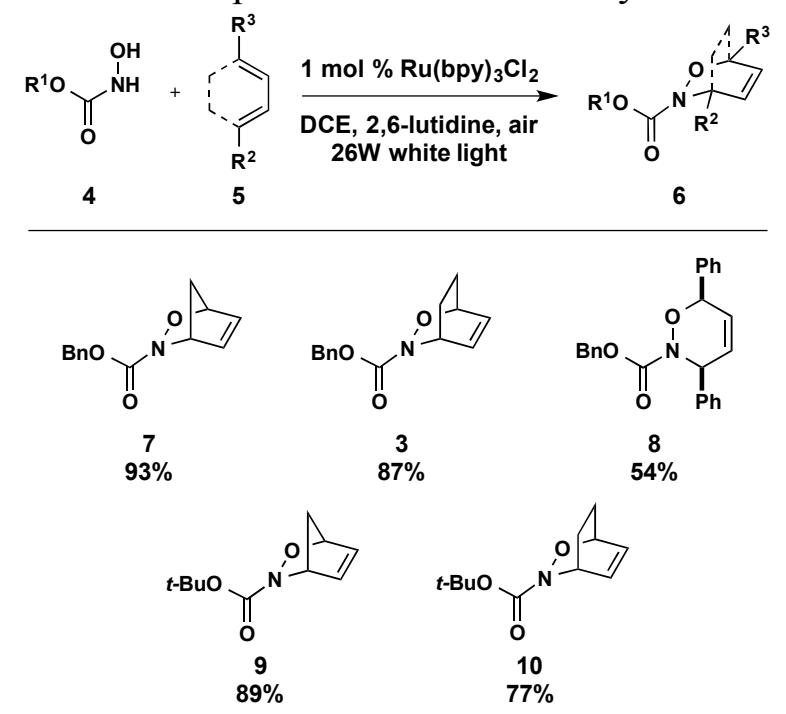

While the Diels-Alder reaction with nitrosoformate intermediates is known to be a highly efficient reaction, ${ }^{18}$ the corresponding ene reaction of nitrosoformate intermediates often suffers from poor yields due to the over-oxidation of the allylic hydroxylamine products. ${ }^{21}$ Recent efforts have been undertaken by a number of research groups to circumvent this known decomposition reaction, ${ }^{22}$ and thus the ene reaction has proven to be an effective tool for evaluating the mildness of oxidation reaction conditions. ${ }^{7}$ In this context, we elected to test our newly developed oxidation conditions with a subset of olefin partners. We were delighted to find that the ene adducts were readily formed under our optimized conditions with no observable product decomposition (Table 3). As with other studies, the efficiency of the ene reaction is directly correlated to the substitution of the olefin; fully substituted olefins, such as 2,3-dimethylbutene, form the corresponding allylic hydroxylamine in quantitative yield (13). In contrast, mono-substituted olefins such as 1-octene react with nitrosocarbonyl compounds with reduced yields (17). In each case, the photoredox conditions compared favorably with previous oxidative nitrosocarbonyl ene methodologies (13-17). ${ }^{1}$ Based on these results, we envision that these conditions can be utilized for a wide variety of reaction platforms and will facilitate the expansion of nitrosocarbonyl chemistry into previously unexplored areas of organic synthesis. 
Table 3. Scope of nitrosocarbonyl ene reaction under photoredox conditions

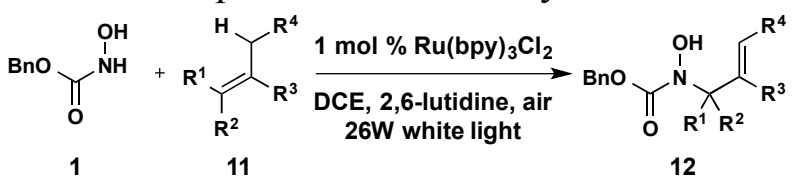<smiles>C=C(CC)C(C)(C)N(O)C(=O)O[Ga]C(=O)c1ccccc1</smiles>

13<smiles>O=C(O[C@@H](Br)c1ccccc1)N(O)C1C=CCCC1</smiles>

14
$68 \%$<smiles>C=C(CN(O)C(=O)OCc1ccccc1)c1ccccc1</smiles>

15<smiles>C/C=C/C=C/C(=N)N(O)C(=O)O[Ga]C(=O)c1ccccc1</smiles>

16

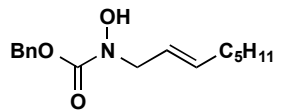

$34 \%$

Encouraged by the mildness of our reaction conditions, we next elected to explore the efficiency of temporal control for our optimized conditions. While on-off studies are not normally performed for photoredox reactions in small molecule chemistry, this type of experiment is regularly conducted with photoredox polymerizations, ${ }^{12,23}$ and is a prerequisite for transitioning a methodology into a number of materials science applications such as the patterning of functionalized surfaces. ${ }^{13}$ Therefore, we were delighted to find that the reaction could be effectively turned on and off based on the presence or absence of light. The reaction showed no reduction in efficiency even after iteratively turning the light on and off. Moreover, the reaction could even be shut off for extended periods of time (e.g. 18 hours) and started again once the light was reintroduced, highlighting a unique element of control never exploited for the generation of nitrosocarbonyl intermediates (Figure 2).

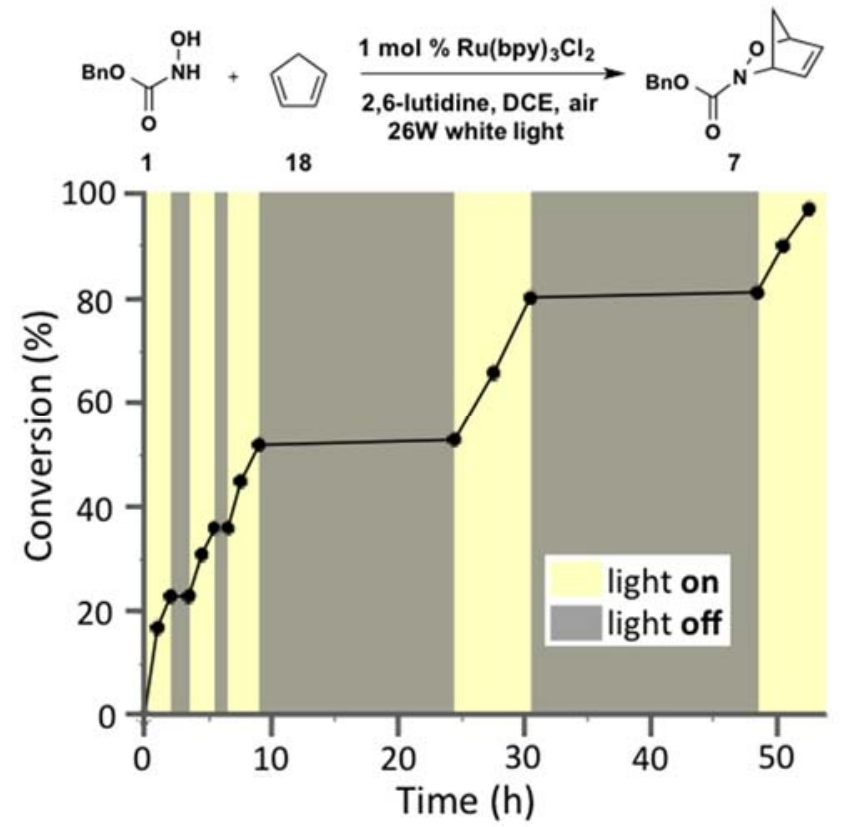

${ }^{a}$ Reactions conducted using dimethyl terephthalate as the internal standard. ${ }^{b}$ Aliquots were removed at the indicated times and conversion was determined by ${ }^{1} \mathrm{HNMR}$ analysis

Figure 2. On-off studies for the developed photoredox oxidation

Eager to demonstrate application of these conditions in a materials setting, we decided to employ our photoredox conditions for the synthesis of a nitroso-Diels-Alder block copolymer 21. ${ }^{24}$ Hydroxamic acid terminated PEG polymer (2k mPEG-HA) 19 was allowed to react under slightly modified reaction conditions with cyclopentadiene end-capped polystyrene polymer (12k PS-Cp) 20. After 24h, complete 
conversion of $\mathbf{2 0}$ was observed and block copolymer $\mathbf{2 1}$ was successfully isolated by trituration in methanol-water (1:1).

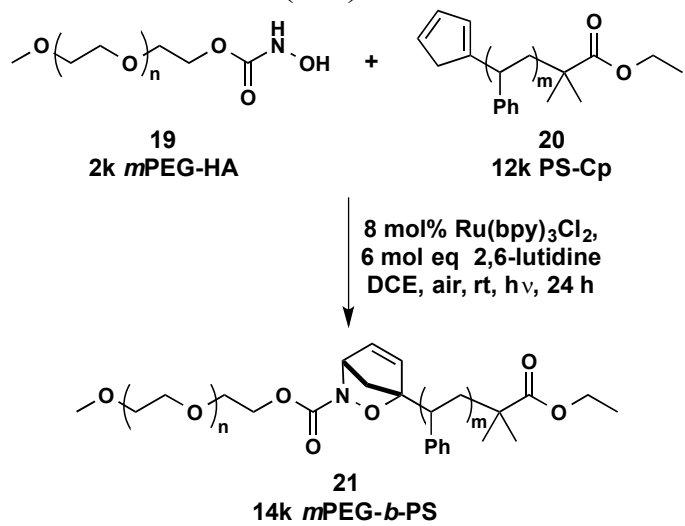

Scheme 1. Photoredox catalyzed synthesis of nitroso-Diels-Alder block copolymer 21

We next explored the distance dependence of our newly developed reaction conditions. For the design of this experiment, the lights were placed at a variable distance away from the sidewall of the reaction flask and the reaction was monitored periodically for conversion. As expected, when the lights were touching the sidewall of the flask, the reaction proceeded the fastest, with a rate paralleling our onoff study. As the lights were moved further from the flask, the reaction rate dropped precipitously. Based on these results, there is a clear spatial dependence of the reaction rate: the intensity of the light has a direct effect on the reaction (Figure 3). Based on the distance dependence and the on-off studies, we believe that this reaction has the potential to find widespread use in applications where temporal and spatial control are desired, and our studies in this area will be reported in due time.

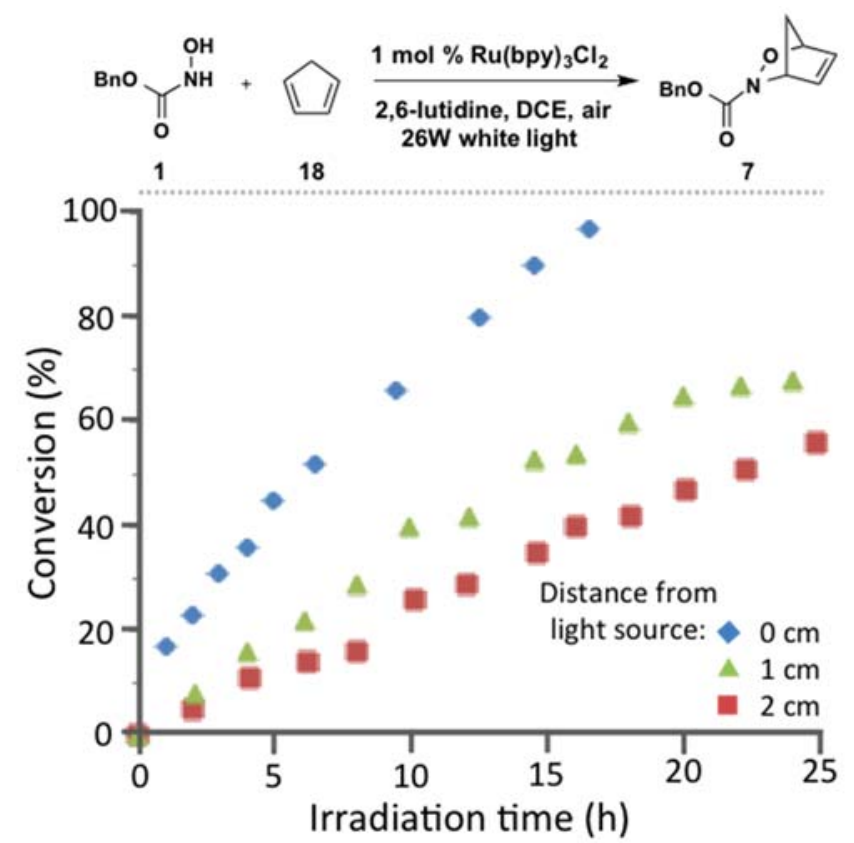

${ }^{a}$ Reactions conducted using dimethyl terephthalate as the internal standard. ${ }^{b}$ Aliquots were removed at the indicated times and conversion was determined by ${ }^{1} \mathrm{HNMR}$ analysis. ${ }^{c}$ The $26 \mathrm{~W}$ lights were placed at the indicated distances relative to the sidewall of the reaction vessel.

Figure 3. Distance dependence of photoredox oxidation

Based on the trends we observed during the reaction development, we were interested in further exploring the mechanism. In particular, we wanted to distinguish between a photoredox mechanism and a mechanism involving singlet oxygen. In order to probe this, we turned to Stern-Volmer studies to confirm the direct interaction between the catalyst and the Cbz-protected hydroxylamine. ${ }^{25}$ As expected, the magnitude of fluorescence of the catalyst had a linear dependence on the concentration of the Cbz- 
protected hydroxylamine, ${ }^{26}$ indicating an interaction between the excited state of the catalyst and the Cbz-protected hydroxylamine (Figure 4). In contrast, no fluorescence quenching was observed in the presence of varying concentrations of the diene (See SI for more information). Based on these results, we propose that the excited state of the catalyst $\left(\mathrm{Ru}(\mathrm{bpy}){ }_{3} \mathrm{Cl}_{2}{ }^{*}\right)$ is directly oxidizing the Cbz-protected hydroxylamine to the corresponding radical cation, consistent with the known redox potentials of the catalyst excited state $\left(\mathrm{E}_{1 / 2}=1.08 \mathrm{~V} \text { vs } \mathrm{Ag} / \mathrm{AgNO}_{3}\right)^{8}$ and the $\mathrm{Cbz}$-protected hydroxylamine $\left(\mathrm{E}_{\mathrm{p} / 2}=0.95 \mathrm{~V}\right.$ vs $\mathrm{Ag} / \mathrm{AgNO}_{3}$, see supporting information). The subsequent reduction of molecular oxygen forms the corresponding superoxide radical, which facilitates the conversion of the Cbz-hydroxylamine radical cation to the nitrosocarbonyl species (Figure 5A).

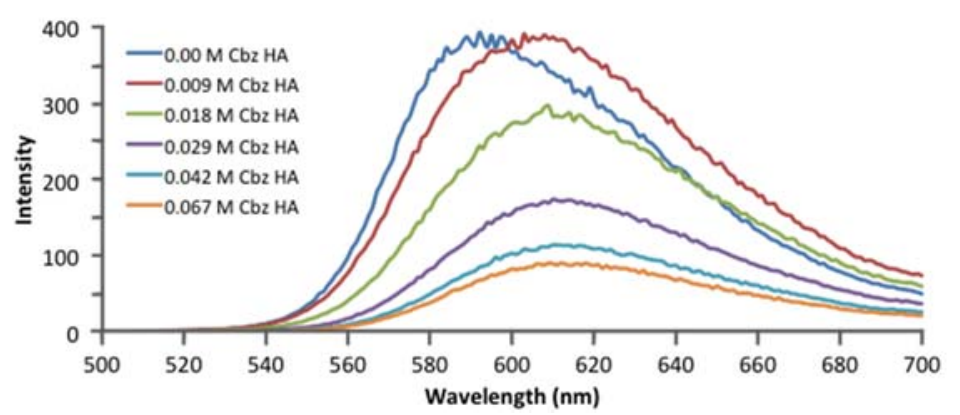

${ }^{a}$ performed in a sealed cuvette under an atmosphere of argon using $1 \mathrm{mg} / \mathrm{mL}$ of $\mathrm{Ru}(\mathrm{bpy})_{3} \mathrm{Cl}_{2} \bullet 6 \mathrm{H}_{2} \mathrm{O}$ in 1,2-dichloroethane.

Figure 4. Fluorescence quenching experiment with Cbz-protected hydroxylamine

To explore the mechanism further, we tested the reaction efficiency in the presence of a known singlet oxygen sensitizer, tetraphenylporphyrin (TPP). ${ }^{27}$ To our surprise, upon irradiation of the reaction, a small amount of hetero-Diels-Alder adduct was observed, although additional aliquots of cyclohexadiene were added periodically ( 3 equivalents every $2 \mathrm{hrs}$ ), due to competing consumption of the diene by singlet oxygen. ${ }^{20}$ Under these conditions, a significant amount of both the endoperoxide and ring-opened 4-hydroxy-2-cyclohexenone were isolated, ${ }^{19}$ along with the desired nitrosocarbonyl HDA adduct (Eq. 1). Under the optimized reaction conditions, direct energy transfer from $\mathrm{Ru}(\mathrm{bpy}) \mathrm{Cl}_{2}{ }^{*}$ to molecular oxygen will produce singlet oxygen, which can potentially oxidize the Cbz-protected hydroxylamine directly and form the corresponding nitrosocarbonyl compound (Figure 5B).

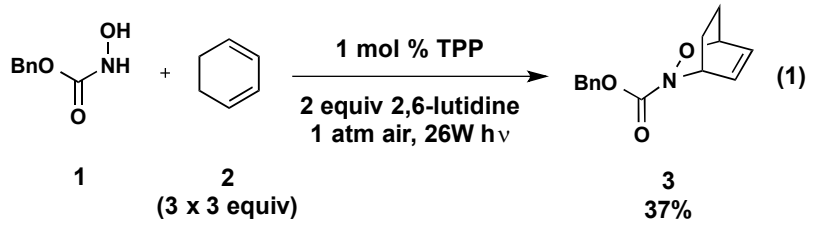

Despite the results using TPP, we believe that the reaction proceeds predominantly through a photoredox mechanism (Figure 5A), based on the compatibility of redox potentials between the hydroxylamine and $\mathrm{Ru}(\mathrm{bpy}){ }_{3} \mathrm{Cl}_{2}{ }^{*}$, Stern-Volmer studies, and on the lack of formation of products derived from singlet oxygen under the optimized conditions. However, at this time a singlet oxygenmediated mechanism cannot be ruled out (Figure 5B). 


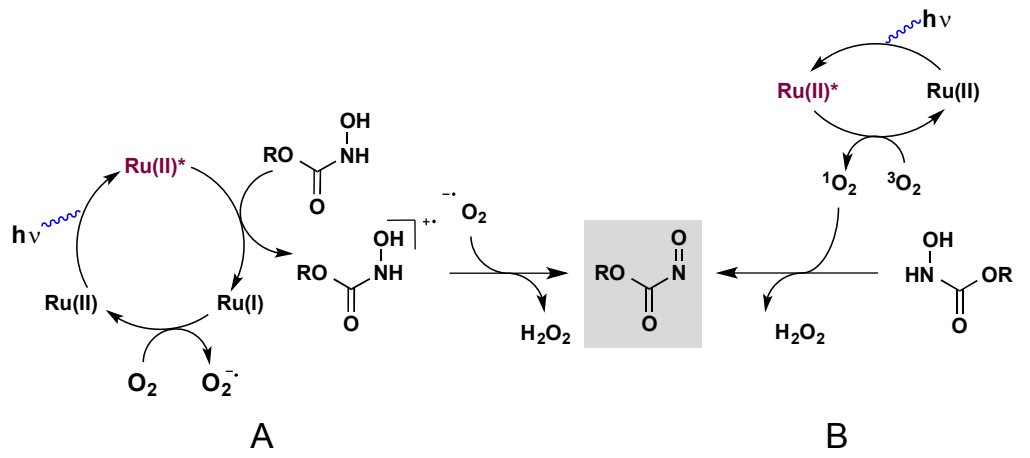

Figure 5. Proposed mechanisms for the photoredox generation of nitrosocarbonyls; A) Photoredox catalyzed oxidation; B) Singlet oxygen mediated oxidation.

In conclusion, the developed photoredox conditions provide a unique pathway to generate transient nitrosocarbonyl intermediates with both temporal and spatial control, demonstrated by the capacity to turn the reaction on and off and the distance dependence. Additionally, the reaction conditions are sufficiently mild so as to not decompose the ene products, suggesting the oxidation methodology can be used to explore new frontiers of nitrosocarbonyl chemistry. The reaction is operationally simple to perform, using lights purchased from a local hardware store, reagent grade solvents, air as the terminal oxidant and a readily available photoredox catalyst. We envision, based on the results, that this newly developed methodology has significant potential utility both in the context of small molecule chemistry and in the applied context of biology or materials science.

Acknowledgments We thank UCSB and MRSEC program (UCSB MRL) of the National Science Foundation (DMR 1121053) for financial support, and Profs. B. Fors and R.D. Little for helpful discussions.

Supporting Information Material associated with this publication is available free of charge in the online version.

\section{References}

1. Frazier, C. P.; Engelking, J. R.; Read de Alaniz, J., J. Am. Chem. Soc. 2011, 133, 10430.

2. (a) Frazier, C. P.; Bugarin, A.; Engelking, J. R.; Read de Alaniz, J., Org. Lett. 2012, 14, 3620;

(b) Chaiyaveij, D.; Cleary, L.; Batsanov, A.; Marder, T. B.; Shea, K. J.; Whiting, A., Org. Lett. 2011, 13, 3442 .

3. (a) Frazier, C. P.; Sandoval, D.; Palmer, L. I.; Read de Alaniz, J., Chem. Sci. 2013, 4, 3857; (b)

Sandoval, D.; Frazier, C. P.; Bugarin, A.; Read de Alaniz, J., J. Am. Chem. Soc. 2012, 134, 18948.

4. (a) Adamo, M. F. A.; Bruschi, S., J. Org. Chem 2007, 72, 2666; (b) Flower, K. R.; Lightfoot, A. P.; Wan, H.; Whiting, A., J. Chem. Soc., Perkin Trans. 1 2002, 2058; (c) Iwasa, S.; Tajima, K.;

Tsushima, S.; Nishiyama, H., Tetrahedron Lett. 2001, 42, 5897; (d) Atkinson, D.; Kabeshov, M. A.; Edgar, M.; Malkov, A. V., Adv. Synth. Cat. 2011, 353, 3347.

5. (a) Baidya, M.; Griffin, K. A.; Yamamoto, H., J. Am. Chem. Soc. 2012, 134, 18566; (b) Kano, T.; Shirozu, F.; Maruoka, K., Org. Lett. 2014, 16, 1530; (c) Maji, B.; Baidya, M.; Yamamoto, H., Chem. Sci. 2014, 5, 3941; (d) Maji, B.; Yamamoto, H., Angew. Chem. Int. Ed. 2014, 53, 8714.

6. $\quad$ Kano, T.; Shirozu, F.; Maruoka, K., J. Am. Chem. Soc. 2013, 135, 18036.

7. $\quad$ Palmer, L. I.; Frazier, C. P.; Read de Alaniz, J., Synthesis 2014, 46, 269.

8. (a) Narayanam, J. M. R.; Stephenson, C. R. J., Chem. Soc. Rev. 2011, 40, 102; (b) Prier, C. K.; Rankic, D. A.; MacMillan, D. W. C., Chem. Rev. 2013, 113, 5322; (c) Tucker, J. W.; Stephenson, C. R. J., J. Org. Chem 2012, 77, 1617. 
9. (a) Ischay, M. A.; Lu, Z.; Yoon, T. P., J. Am. Chem. Soc. 2010, 132, 8572; (b) Lin, S.; Ischay, M. A.; Fry, C. G.; Yoon, T. P., J. Am. Chem. Soc. 2011, 133, 19350; (c) Lin, S.; Padilla, C. E.; Ischay, M. A.; Yoon, T. P., Tetrahedron Lett. 2012, 53, 3073.

10. (a) Tucker, J. W.; Narayanam, J. M. R.; Shah, P. S.; Stephenson, C. R. J., Chem. Commun. 2011, 47, 5040; (b) Freeman, D. B.; Furst, L.; Condie, A. G.; Stephenson, C. R. J., Org. Lett. 2011, 14, 94; (c) Dai, C.; Meschini, F.; Narayanam, J. M. R.; Stephenson, C. R. J., J. Org. Chem. 2012, 77, 4425; (d) Bergonzini, G.; Schindler, C. S.; Wallentin, C.-J.; Jacobsen, E. N.; Stephenson, C. R. J., Chem. Sci. 2014, 5, 112.

11. (a) McNally, A.; Prier, C. K.; MacMillan, D. W. C., Science 2011, 334, 1114; (b) Pirnot, M. T.; Rankic, D. A.; Martin, D. B. C.; MacMillan, D. W. C., Science 2013, 339, 1593; (c) Petronijević, F. R.; Nappi, M.; MacMillan, D. W. C., Journal of the American Chemical Society 2013, 135, 18323; (d) Zuo, Z.; MacMillan, D. W. C., J. Am. Chem. Soc. 2014, 136, 5257; (e) Zuo, Z.; Ahneman, D. T.; Chu, L.; Terrett, J. A.; Doyle, A. G.; MacMillan, D. W. C., Science 2014, 345, 437.

12. (a) Fors, B. P.; Hawker, C. J., Angew. Chem. Int. Ed. 2012, 51, 8850; (b) Treat, N. J.; Fors, B. P.; Kramer, J. W.; Christianson, M.; Chiu, C.-Y.; Alaniz, J. R. d.; Hawker, C. J., ACS Macro Lett. 2014, 3, 580.

13. (a) Fors, B. P.; Poelma, J. E.; Menyo, M. S.; Robb, M. J.; Spokoyny, D. M.; Kramer, J. W.; Waite, J. H.; Hawker, C. J., J. Am. Chem. Soc. 2013, 135, 14106; (b) Poelma, J. E.; Fors, B. P.; Meyers, G. F.; Kramer, J. W.; Hawker, C. J., Angew. Chem. Int. Ed. 2013, 52, 6844.

14. Nguyen, J. D.; Tucker, J. W.; Konieczynska, M. D.; Stephenson, C. R. J., J. Am. Chem. Soc. 2011, 133, 4160.

15. (a) Xu, Y.; Alavanja, M.-M.; Johnson, V. L.; Yasaki, G.; King, S. B., Tetrahedron Lett. 2000, 41, 4265. (b) For thermal HNO release from a polymer, see: Peterson, G.I.; Church, D. C.; Yakelis, N. A.; Boydston, A. J. Polymer 2014, 55, 5980.

16. Teo, Y. C.; Pan, Y.; Tan, C. H., ChemCatChem 2013, 5, 235.

17. (a) Cohen, A. D.; Zeng, B.-B.; King, S. B.; Toscano, J. P., J. Am. Chem. Soc. 2003, 125, 1444;

(b) O'Bannon, P. E.; Sülzle, D.; Schwarz, H., Helvetica Chimica Acta 1991, 74, 2068.

18. (a) Bodnar, B. S.; Miller, M. J., Angew. Chem. Int. Ed. 2011, 50, 5630; (b) Streith, J.; Defoin, A., Synthesis 1994, 1107; (c) Vogt, P. F.; Miller, M. J., Tetrahedron 1998, 54, 1317; (d) Yamamoto, Y.;

Yamamoto, H., Eur. J. Org. Chem. 2006, 2031.

19. Kornblum, N.; DeLaMare, H. E., J. Am. Chem. Soc. 1951, 73, 880.

20. (a) Clennan, E. L.; Pace, A., Tetrahedron 2005, 61, 6665; (b) Clennan, E. L., Tetrahedron 1991, 47, 1343; (c) Adam, W.; Prein, M., Acc. Chem. Res. 1996, 29, 275.

21. (a) Adam, W.; Krebs, O., Chem. Rev. 2003, 103, 4131; (b) Iwasa, S.; Fakhruddin, A.;

Nishiyama, H., Mini-Rev. Org. Chem. 2005, 2, 157; (c) Baidya, M.; Yamamoto, H., Synthesis 2013, 45, 1931.

22. (a) Quadrelli, P.; Campari, G.; Mella, M.; Caramella, P., Tetrahedron Lett. 2000, 41, 2019; (b)

Quadrelli, P.; Mella, M.; Caramella, P., Tetrahedron Lett. 1999, 40, 797; (c) Adam, W.; Bottke, N.;

Krebs, O.; Saha-Moller, C. R., Eur. J. Org. Chem. 1999, 1963; (d) Fakhruddin, A.; Iwasa, S.;

Nishiyama, H.; Tsutsumi, K., Tetrahedron Lett. 2004, 45, 9323; (e) Kalita, B.; Nicholas, K. M.,

Tetrahedron Lett. 2005, 46, 1451.

23. (a) Shanmugam, S.; Xu, J.; Boyer, C., Macromolecules 2014, 47, 4930; (b) Xu, J.; Jung, K.; Atme, A.; Shanmugam, S.; Boyer, C., J. Am. Chem. Soc. 2014, 136, 5508; (c) Xu, J.; Jung, K.; Boyer, C., Macromolecules 2014, 47, 4217.

24. Samoshin, A. V.; Hawker, C. J.; Read de Alaniz, J., ACS Macro Letters 2014, 3, 753.

25. Turro, N. J., Modern Molecular Photochemistry. Benjamin/Cummings: Menlo Park, CA, 1978.

26. Upon the addition of $\mathrm{N}$-Cbz hydroxylamine a distinct red-shift is observed in the fluorescence spectrum. At this time, the observed effect is inexplicable and efforts are underway to elucidate the cause.

27. DeRosa, M. C.; Crutchley, R. J., Coord. Chem. Rev. 2002, 234, 351.

28. (a) Zhu, M.; Zheng, N., Synthesis 2011, 2011, 2223; (b) Cecere, G.; König, C. M.; Alleva, J. L.; MacMillan, D. W. C., J. Am. Chem. Soc. 2013, 135, 11521. 


\section{Graphical Abstract}

Title

Charles P. Frazier, Leoni I. Palmer, Andrey V. Samoshin and Javier Read de Alaniz*

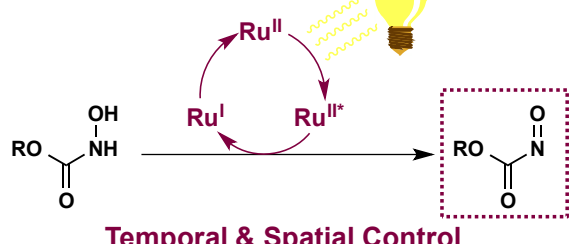

Temporal \& Spatial Control

-Diels-Alder \& ene reaction compatible -Light regulated conjugation tool 